Note: This is a pre-copy-editing, author-produced PDF of an article accepted for publication in Drugs: education, prevention and policy following peer review. The definitive publisher-authenticated version [Mayock P (2005) 'Scripting' risk: Young people and the construction of drug journeys, Drugs: education, prevention and policy, 12(5), 349-368] is available online at http://www.informaworld.com/smpp/content db=all content=a727164035

\title{
'Scripting' risk: Young people and the construction of drug journeys
}

\author{
PAULA MAYOCK \\ Trinity College, Dublin 2, Ireland
}

Published in: Drugs: education, prevention and policy, Vol. 12, No. 5, October 2005: 349-368

Copyright: Taylor \& Francis

The concept of risk, and its centrality to social life, is theoretically much discussed within late modernity. This paper examines young people's drug use and their drug transitions within a framework of risk drawing on findings from a longitudinal ethnographic study of drug use among young people in a Dublin inner-city community. Fifty-seven young people aged between 15 and 19 years, including non-users, recreational, and problematic drug users, were recruited into the study in

1998. Contact was re-established with 42 of the study's participants in 2001. Individual interviews and focus group discussions, supported by prolonged participation within the study site, were the primary methods of data collection. Drawing on the young people's situated accounts of their drug-taking events, routines, and practices across time, the findings highlight the complex social negotiations involved in the construction of drug journeys. Analyses of change in drug use behaviour over the study period demonstrate that drug transitions unfold alongside dynamic and changing perceptions of safety and risk. Responses to 'risk' within youth drug scenes were contextually shaped, open to situational revision over time, and, in many instances, drug taking was habitual, not calculated. Put differently, young people 'script' risk as they gain experience in the world. The type of calculus involved in the making of drug journeys is fluid and relational, socially contingent rather than static, and subject, at times, to constrained agency linked to social and economic marginalization. It is argued that models of risk that rely on individualistic and rationalistic assumptions struggle to accommodate the fluidity and contradiction that characterizes much drug use. Implications for strategies and initiatives aimed at reducing drug-related harm are discussed.

Keywords: Youth and drugs, drug transitions, risk, individualism, ethnography

\section{Introduction}

Risk is a central discourse among those that surround young people, in general, and young drug users, in particular. The very mention of the words heroin, cocaine, or ecstasy immediately conjure up images of danger, and drugs are rarely discussed, whether in the media, the living room, or by experts, without allusions to 'at risk' individuals, risk behaviours, and 'risky' choices. The concept of risk and its derivatives, most prominently, the technology of risk factor research, occupies a central position within drugs discourse, providing a framework for the identification of drug 'problems' and at risk populations, the mapping of causal factors, and the identification of predictors of drugs 'misuse'. Risk, as Douglas (1990) puts it, has come to mean danger and 'high risk means a lot of danger'. 
More broadly, the concept of risk has been used in the domain of social theory to identify, define, and organize analyses of 'post' and 'late' modern industrialized societies (Beck, 1992; Douglas, 1992; Giddens, 1991). It is claimed that we live in a

'risk society' (Beck, 1992) and recent literature has portrayed risk as a dominant feature of contemporary life. For both Beck (1992) and Giddens (1991), one of the major

consequences of modernization is a trend towards individualization, so that more aspects of everyday life are considered subject to human agency. The process of individualization, Beck (1997, p. 96) writes, means that the 'standard biography becomes a chosen biography'. In a similar way, Giddens (1991) talks about the 'reflexive project of the self ', the idea that, in a post modern society, it is more up to the individual to shape one's own identity and to make decisions. From this perspective, people are involved in the 'everpresent exercise' (Giddens, 1991, p. 114) of risk assessment in which risks are weighed up and managed at an individual level. All of this suggests a repositioning of self in relation to risk, since individualization increasingly places responsibility on the individual for taking risks and for making risk-related decisions In a critical sense, it signifies a shift in the way in which we conceptualize risk since people of all ages are increasingly positioned as choosing, self-governing agents (Nettleton, 1997; Petersen, 1996). This highlights a moral dimension to risk assessment, as well as ways in which the perpetrators of risk can be held accountable for their behaviour: those who act responsibly avoid risk, whereas those who behave irresponsibly are themselves to blame for the risks they take (Douglas, 1990, 1992). What implications do these ideas have for our understanding of, and response to, illicit drug use among the young? It is useful to consider this question in light of the rise to prominence of notions of choice and decision-making within the youth drugs literature.

The 1990s brought about significant shifts in the youth drugs landscape throughout Europe. Against a backdrop of increased prevalence rates for drug experimentation and use, the emerging picture signalled a quite dramatic upward trend in drug use among teenagers and youth adults (Calafat et al., 1999; European Monitoring Centre for Drugs and Drug Addiction, 2002, 2003). While, at the turn of the century, drug use itself could not claim to have become the true 'norm', it had clearly moved from its former exceptional status (South, 1999). A key characteristic of this more widespread pattern of illicit drug consumption relates to women's participation in youth drug scenes and their high rates of drug use (Henderson, 1999; Hibell et al., 1997, 2000; Measham, 2002). Moreover, today's young drug users come from a wide range of socio-economic backgrounds and a large majority are either employed full-time or in higher education (Kohn, 1997; Mayock, 2001; McElrath \& McEvoy, 1999; Measham, Aldridge, \& Parker, 2001). In several countries, including Ireland, drug use, traditionally associated with poor places and poor people, has come to be recognized as a more mainstream activity. Correspondingly, the traditional axes of class and gender, which to a considerable extent delineated past drug use configurations and trends, are thought to have less analytic hold in a world where drug use is neither a strictly marginal nor a predominantly male activity.

The rise to prominence of illicit drug use within contemporary 'going out' scenes has probably been best demonstrated in Parker and colleagues' (1998) longitudinal study conducted in the North-West of England. This research found that young people's drug use preferences altered as they gained experience and learned more about the effects, benefits, and risks of individual drugs. Placing the high rate of drug consumption uncovered in their research in the context of broader societal changes rendering risk an ever-present feature of contemporary social life (Beck, 1992), Parker and colleagues (1998, p. 28) draw attention to a decision-making process in relation to drug use, stressing the cost/benefit assessments that inform young people's drug decisions. Correspondingly, the study highlights an array of factors (pleasure, friends and partner response, family, health risks, and bad drug experiences) that influence young people's drug choices and the manner in which they assess the benefits and risks of using drugs. This sociological approach emphasizes the situated rationality of risk behaviour. Accordingly, what is considered a 
cost, a benefit, or a risk is not static, nor is it necessarily shared among individuals: it is situated instead within different social contexts of belief and behaviour. Beyond emphasising drug use situations as important determinants of drug use, Parker and colleagues place young people's 'reasoned choices' about drugs (Williams \& Parker, 2001, p. 411) in the context of contemporary adolescent/ young adult lifestyles where consumption is central, the move to independence is postponed, and traditional adult 'responsibilities' (marriage, a family, and parenting) are delayed. Living in a risk society demands that young people make rational decisions about consumption and, in relation to drugs, many do this using 'a cost-benefit equation' (Parker, Measham, \& Aldridge, 1998, p. 133). ${ }^{1}$

The study of Parker and colleagues (1998) is one of a number that have drawn attention to active decision-making on the part of young people in relation to the use and non-use of illicit drugs (Boys et al., 2000; Coffield \& Gofton, 1994; Measham et al., 2001), signalling a positive move away from notions of personal inadequacy and passivity. In particular, it marks a rejection of deterministic and pathological explanations for drug consumption among the young in favour of explanations that give the goal orientated, rational, and everyday aspects of drug-taking activity a central place. Nonetheless, it is easy to see how talk about the role of choice in drug taking, however well intentioned, can inadvertently dovetail into moral arguments about the need for greater individual responsibility as a means of solving the drugs "problem". Paradoxically then, the emphasis on rational decision-making, guided in the main by cost/benefit analysis, can serve to reinforce the notion of drug users as "other", seeing them not simply as outside the social order, but as outsiders who refuse to conform to the advice of experts. Cost-benefit approaches have been criticized for treating individuals as free agents in terms of their response to risk (Denscombe, 1993) and for viewing behaviour as a characteristic of the individual rather than as varying between social relationships (Friedman, Curtis, Neaigus, Jose, \& Desjarlais, 1999). They have also been criticized for their lack of attention to the habitual nature of much risk-taking (Bloor, 1995; Bloor et al., 1992; Hart \& Boulton, 1995; Rhodes, $1995,1997)$ and for failing to pay attention to how "risk environments" (Rhodes, 2002) and people's embeddedness within particular social, cultural and economic contexts influence their drug use (Moore, 2004).

This paper examines young people's drug use and their drug transitions within a framework of risk. Of particular interest are young people's perceptions of various salient aspects of drug-related risk, the subjective logic that guides and sustains their perspectives on risk boundaries, and how this may alter and/or become redundant over time. To this end, the "scripts" metaphor is used as an analytic tool to examine ways in which they produce and rationalize their drug "stories". Scripts are conceptually useful for getting at how various patterns and styles of drug use and non-use are accomplished over time, while leaving room for individual actors to change, innovate, revise, and edit their drug scripts at every level in light of their social environments, encounters, and emerging experiences The notion of scripting is used here on the assumption that individuals actively learn, employ, and innovate scripts for their own drug use behaviour while, at the same time, acknowledging that there are circumstances, both social and personal, that militate against the generation of safer scripts. The analysis presented in later sections demonstrates that cost/benefit analysis is only one dimension, and frequently a marginal component, of young people's drug-related decisions. Highlighting the complexity of the risk practices and behaviours surrounding young people's drug journeys, it exposes the limits of individualism and, in particular, its failure to capture the context-dependent nature of risk decisions and the complex social negotiations and constraints that characterize much drug-taking. 


\section{Methods}

The data for this analysis are drawn from a longitudinal ethnographic study of drug use in an inner-city Dublin locality where drug problems are concentrated. The research sought detailed knowledge and understanding of young people's exposure to illicit drugs, and of their use and non-use of a range of substances (including alcohol and tobacco) across time, within their natural setting, that is, the community where they live. Ethnographic fieldwork was conducted in two adjacent neighbourhoods, which lie within 3 kilometres of Dublin's city centre. The areas selected for study are part of a broader geographical area that suffers from several 'joined up' problems of social exclusion (MacDonald \& Marsh, 2001), including long-term concentrated poverty, high unemployment rates, poor housing, and low educational attainment. Both are well know locally and nationally for their highprofile drugs problem and are nested in a postal district estimated to host the highest number of male opiate users in the State (Comiskey, 1998). Like other communities in the Greater Dublin area identified as hosting a disproportionate number of problem drug users, the clustering of drug problems in the locality has a 20 -year history and can be traced to Ireland's 1980s heroin epidemic (Dean, Lavelle, Butler, \& Bradshaw, 1984; Dean, O'Hare, O'Connor, Kelly, M., \& Kelly, G., 1985).

Fieldwork was initiated during the latter months of 1997, during which time attention focused on gathering various sources of local knowledge, including information about types of drug using groups and the locations where young people 'hung out'. At a conceptual level, these early months of engagement within the study site permitted the identification of sources of key theoretical contrasts, thus enabling the study of variability along dimensions such as age, gender, youth venues, drug use status, and risk behaviour. The formal recruitment process, initiated during the early months of 1998, was essentially a social one, involving negotiation and renegotiation throughout the entire course of fieldwork; it involved gaining entry to youth venues and street-based settings, moving through networks of friends, and, above all else, the ability to respond to new lessons and changing circumstances in the field. Recruitment relied to a considerable extent particularly during the early months, on 'snowball' sampling (Biernacki \& Waldorf, 1981). However, as time progressed, the use of targeted sampling (Watters \& Biernacki, 1989) helped to circumvent the risk of bias arising from the exclusive use of snowball or chain referral techniques. Fiftyseven young people (24 young men and 33 young women), ranging in age between 15 and 19 years, were recruited into the study over a 10-month phase of intense fieldwork during 1998. On returning to the field in 2001, contact was re-established with 42 of the study's participants (16 young men and 26 young women). During both the initial and follow-up phases of fieldwork, individual in-depth interviews, supported by prolonged participation with young people within various neighbourhood settings and youth venues, were the primary data collection methods. Six focus group discussions, with a total of 24 participants, were also conducted during Phase I of the study. ${ }^{2}$ Finally, during Phase II fieldwork, a number of the study's young people participated in a small-scale photography project designed to capture key characteristics of the social landscape. This exercise facilitated the re-establishment of trust and rapport and helped to generate dialogue about continuity and change in community life since the time of initiating the study.

Existing descriptions of drug-involved youth in high risk localities tend to be fragmented, considering only single subgroups (usually heroin users) of this diverse population (cf. Parker, Bakx, \& Newcombe, 1988; Pearson, Gilman, \& Mclver, 1986), and ignoring the overlap and interaction of drug users and non-users within these risk environments. Correspondingly, the sociological significance of the drug use transitions of young people who live in high-risk environments remains underdeveloped (MacDonald \& Marsh, 2002). This study aimed to tap into a diverse range of drug-related experiences, thereby creating the space to examine how marginal contexts impact differentially on young people's drug biographies. The initial sample comprised young people who were categorized as 'abstainers' ( $n^{1 / 418)}$, 'drug takers' ( $n^{1 / 421)}$, or 'problem drug takers' $\left(n^{1 / 418)}\right.$ at the point of 
recruitment in $1998 .{ }^{3}$ Abstainers were non-users of illicit drugs at the time of their initial interview; drug takers were users of one or more illicit substance but they did not consider their drug consumption to be problematic; finally, problem drug takers were primarily smokers and/or intravenous users of heroin who self-identified as addicted and/or reported social, health-related, financial, and/or psychological problems arising from their drug consumption. Throughout the study, categorization was based on young people's views and perceptions of their drug use status at the time of interview. In other words, classification hinged on 'the categories of distinctions that actors recognize and respond to' (Wax, 1967, p. 329); it emerged through a process of self-nomination and was based on young people's perceptions of the risks, benefits, and consequences of their drug use. This approach precluded the imposition of 'outsider' judgement and created the scope to examine the logic underpinning young people's risk positions as they moved in to, and out of, drug use at various levels.

\section{Drug use patterns and transitions}

There was enormous diversity, both within and between the three categories of research participants in terms of the type, level, and frequency of their drug consumption. Moreover, drug journeys subsequent to initiation (which occurred at 13.3 years and 12.4 years for the study's drug takers and problem drug takers, respectively) were complex, variable, and diverse. Abstainers, as stated earlier, were non-users of illicit substances at Phase I. However, one-third of the follow-up sample had moved to drug use by the time of their Phase II interview. The majority of the study's drug takers (including those abstainers who made the transition to drug use) shared a perspective that accepted 'soft' drug use but rejected heroin and, to a lesser extent, cocaine. Nonetheless, the drug consumption styles of these social/recreational users varied greatly, with some reporting more regular and sustained patterns of use. In general, drug takers recounted an extensive repertoire of drug experiences; many were daily cannabis smokers and, by Phase II of the study, the vast majority had sampled at least five drugs, including cannabis, amphetamines, ecstasy, LSD, and/or inhalants. Additionally, by the time of conducting follow-up interviews, a large number had incorporated cocaine into their drug repertoires, suggesting a marked shift in previously defined boundaries of 'acceptable' drug use, which tended to exclude cocaine. Polydrug use was the norm for this group and a large number reported a phase of regular stimulant drug use, dominated by ecstasy and amphetamines. At the time of conducting follow-up interviews, three of the study's Phase I drug takers self-nominated as problem drug takers, with all three reporting the transition to heroin use and simultaneously reporting social, financial, and health difficulties arising from their drug consumption. Finally, the study's problem drug takers initiated drug use early and they quickly became immersed in street-based drug scenes. Their heroin 'career' was characterized by 'chasing' (i.e., smoking heroin), followed by the transition, in almost all cases, to intravenous drug use. By the time of conducting Phase II fieldwork, all had sought treatment. However, the majority continued to struggle with the recovery process, reporting several episodes of relapse and periods on and off heroin following their early attempts to address their drug-related problems.

Across the sample, levels of drug involvement ranged from non-use to occasional or moderate drug use through to problematic levels of drug involvement, highlighting the diversity of drug use and non-use within this high-risk locality. Co-existing within the same disadvantaged neighbourhood were young people who adhered strongly to an ethos of abstinence, while across the street, next door, or even in the same household was a likeaged counterpart or sibling who had become fully absorbed into problematic drug use. Furthermore, the drug transitions uncovered over the study period were extraordinarily complex; they did not convey a simple, straightforward pathway and, instead, suggested a multiplicity of changing statuses over time. Young people moved between different drugs and levels of use intensity; some extended their drug repertoires while others stepped back, 
at least for a period, from more regular consumption. Nonetheless, an upward rather than a downward trajectory emerged as the most likely drug pathway during the early to middle and middle to late teenage years. While there were some signs of a 'settling down' or 'maturing out' among both drug takers and problem drug takers by the time of conducting Phase II interviews, many more had extended the range and scope of their drug experience. Furthermore, few of the study's social/recreational drug users had plans to quit illegal drug use, certainly in the short or medium term.

\section{Risking risk}

Risk-taking by young people is often conceptualized as involving danger, loss of control, 'trouble', and probable harm; it carries strong negative connotations and is rarely publicly discussed in terms of pleasurable or positive rewards. Moreover, within the research literature, pleasure remains a relatively neglected dimension of risk-taking among the young (France, 2000; Rhodes et al., 2003) and of the drug use phenomenon generally (Mugford \& O'Malley, 1991). ${ }^{4}$ However, traditional readings of risk-taking as dangerous and undesirable are challenged to a large extent by young people's accounts of the benefits of risk. Their 'vocabularies of motive' for drug use (Weinstein, 1980) provide critical insight, not simply into the appeal of drug consumption; they also tell us a great deal about how young people relate to risk.

Social aspects of drug use dominated practically all narrations of drug-using events and, for a large number of the study's drug users, drug consumption and pleasure were inseparable. A discourse of self-indulgence underpinned many accounts of positive drug experiences and, in many depictions of drug using events, young people presented themselves as motivated by the pleasures of the moment. More than this, practically all recognized that drug use involved taking risks: to consume drugs necessitated exposing oneself to risk and this dimension of risk-taking was an intrinsic part of the psychoactive 'hit'. Joan, a recent ecstasy initiate at the time of her follow-up interview, expressed this idiosyncratic relationship between drug use and risk succinctly:

Oh, don't get me wrong, I think ecstasy is really dangerous myself, you know what I mean? But sometimes it's the risk that gets you.

Joan, 18 years.

Placing oneself in danger by using drugs could, as acknowledged by Joan, lead to risk, but risk also provided an intoxicating sense of pleasurable excitement. For a large number, drug consumption was accepted as incorporating danger, often in association with the unknown. Indeed, to a considerable extent, young people's accounts of the benefits of drug use shift the focus away from fear to the spontaneous, meaningful, and often impulsive character of youthful experience. While not all of the study's drug users championed drugtaking for the sake or benefit of risk, the majority openly acknowledged that using drugs involved potential danger: '. . . there's nothing safe in any of them except for hash ... [but] I am prepared to take risks ... .' (Linda, 20.5 years). The study's drug takers (including those abstainers who made the transition to drug use) simultaneously emphasized the social/recreational nature of their drug taking, drawing attention to the normality rather than the deviancy of their activities, and stressing the situationally appropriate nature of socializing on drugs. These 'competent' and 'responsible' drug users rehearsed accounts that helped them to neutralize anxiety, maintain moral worth, and keep their reputations intact. To this end, they narrated important distinctions between recreational and compulsive drug use, portraying the two groups as opposite ends of the risk spectrum, symbolizing different lifestyle choices and everyday needs, as Laura explained.

[So do you think there's a big difference between people who use drugs recreationally and people who use heroin?] 
Huge difference, yeah, totally different. These people are still working. The person on heroin is not, that person wouldn't be. Two totally different situations. Both of them could die or the one on ecstasy could take one and die as well, but totally different. One is takin' it for a laugh and going out and the other is takin' it because she needs to take it. She's an addict.

Laura, 21 years.

Young people like Laura invariably stressed other valued life projects, including school, college, a job, or a romantic partner, that they prioritized over the fleeting rewards of drug use. Put differently, they claimed to integrate drug taking positively and constructively into their lives and to move easily between the drugs world and the world of work and other responsibilities.

In their talk about drugs, others introduced aspirations linked to 'heroic' risk-taking (Featherstone, 1995; Mitchell, Crawshaw, Bunton, \& Green, 2001). For these young people, participation in local drug scenes conferred social and personal rewards linked to displays of experience, and opened up opportunities for status achievement. These accounts were particularly common among young men and women who became heavily immersed in street-based drug scenes, where they experienced strong exposure to hard drug use and to dealing and scoring activity.

I'm streetwise. I know what's going on out there and you have to learn how to survive. That's what it's about really. You're nothing unless you have that.

Brian, 18 years.

A smaller number of young people portrayed drugs as having therapeutic value in a variety of contexts and situations. Drugs offered a kind of 'cocoon-comfort', opening up a world that provided emotional well-being and calm. Far from being thought of as risky drug consumption provided 'warm immunity from danger' (Feldman, 1968, p. 136). Regular, heavy or 'problematic' drug users, who frequently reported reduced anxiety and intense psychological relief as leading incentives for use, more commonly reported these vocabularies of motive.

Just a very mellow buzz, you're very relaxed and it makes me feel really good. It's like a heavy tiredness and very mellow. It takes you away, especially if you're upset. You don't have to think about a thing.

Gerald, 19 years.

This orientation to drug use, emphasizing psychological release from anxiety, stress, or depression, represents a marked departure from the temporary 'breaks' typically celebrated by the study's social/recreational drug users. For those young people who sought respite from difficult situations and emotions, drugs provided an escape route in the true sense.

Although the term risk is used in late modern society primarily as a synonym for danger and 'bad' outcomes (Beck, 1992; Douglas, 1992; Giddens, 1991), the stories told by the study's young drug users suggest a counter discourse, in which risk-taking is positively embraced in association with pleasure and gain. This discourse is one that apparently 'rejects the ideal of the disembodied rational actor for an ideal of the self' (Lupton, 1999, p. 149). In keeping with this orientation, an important part of young people's risk epistemologies was an interpretation of risk-taking as part of 'living', both in the everyday and the spectacular sense. In many respects, young people appeared to actively pick and choose in a seemingly individualistic manner from the (limited) pleasure landscapes available to them. In this context, it seems vital to bear in mind that drug consumption, and even risky use, may be about anything but a preoccupation with balancing benefit and risk; rather it is about 
such diverse concerns as social expression and 'style', experimentation, group membership, status achievement, or 'escape attempts'.

\section{Scripting risk}

Young people's accounts of their drug transitions over the study period invariably referenced changes in individual or collective risk positions. There are multiple examples of this orientation to drug consumption but, for the purposes of this paper, it is useful to focus on three broad types of drug transitions: the transition to 'new' drugs; the transition to 'dangerous' drugs or risky routes of administration and, finally, what is referred to here as 'imagined' futures in relation to drug use.

\section{The transition to new drugs}

Young people's accounts point strongly to an array of conditions, situations, and experiences that prompted change in their drug use practices, preferences, and choices. In attempting to explore this terrain, and demonstrate the shifts and nuances that characterize the risk perceptions of young people, the role of context cannot be over-emphasized. More than this, much of the narrative material depicting the incorporation of new drugs highlights the ordinary, rather than the extraordinary, nature of these transitions. Young people rarely described the incorporation of new drugs or drug-taking practices without referring to use settings and associated circumstances and individuals. Put differently, drug taking was scripted within familiar social settings, where changes in behaviour often emerged spontaneously. In keeping with this, a large number of young people explained their drug transitions casually, portraying them as largely unexceptional events. Denise, who cited fear as a major deterrent to ecstasy use during her first interview at the age of 15, explained how her sense of apprehension diminished as she became exposed to more positive renditions of the ecstasy 'buzz'.

I used to be afraid to take E. I was afraid I would die. And then I tried a few of them.

[What made you lose that fear?]

I don't know. Everybody was just sayin' that it was a great buzz so I tried it. They [friends] seemed to be alright, it wasn't doing anything bad to them. I only tried half of one the first time. It was great!

Denise, 18 years.

For the majority who extended their drug repertoires, prior sensitivities to danger and potential harm subsided and were replaced by feelings of relative invulnerability. These shifts transpired, often gradually, through immersion in drug scenes, usually in interaction with experienced colleagues or mentors. In this way, new definitions of 'normal' risk (Hunt, 1995) were introduced and learned casually through participation. ${ }^{5}$ This process, involving the 're-vision' or re-drafting of previously constructed risk boundaries, is explicit in Sandra's account of ecstasy initiation.

I used to hear stories about them $(E)$ and I was very afraid to take them so, ah, people were saying, 'Just try it, it's not like the way ya hear it', and all. And I said, 'Ah, no'. And then one night when we were going to a party I says, 'Just give me a half one and l'll see what it's like'. And I got a great buzz out of a half $a$ one and then

I took the other half and got an even better buzz.

Sandra, 18 years. 
Whether in a club, pub, or 'hanging out' at outdoor locations, the presence and teachings of more experienced drug users opened up new ways of framing risk, creating new

possibilities for the construction of drug journeys. In many cases, previously established risk frames altered in response to new experiences. As young people neared their late teenage years, going out occupied a central role, as did their interest in seeking out new experiences, friends, and romantic partners. A large number began to explore new social settings outside of their home neighbourhoods and there was a sense in which abstainers, in particular, realized that drug consumption was not confined to bad neighbourhoods, such as the area where they lived. Laura (a Phase I abstainer) described how her exposure to mainstream drug scenes led her to modify her previous anti-drug stance, paving the way for her first ecstasy hit.

[You told me in your last interview that you were afraid to take E. . .]

Yeah. I always felt that if I took E I would die. I always just thought that because I was always the unlucky one growing up. 'It would be just like what would happen to me if I took one, I would be the one', that is the way I thought about it. Always afraid of actually just swallowing $E$, I had a real fear against it. I suppose

I was so anti-drugs in that kind of way as well. It would have been going against everything I thought about.

[And how do you think that changed or in what way did it change?]

That night in Greenwood [adjacent neighbourhood], well I wasn't going through a good time with me fella [boyfriend] and I just thought if I do this everything will be better and we will get on better and blah, blah, blah. So I just did it, I did half an E and his mates were saying, 'You won't die, of course you won't die, you eejit', and all this shite. So I did it and I didn't feel anything so I took another half and the two of them came up together and it was great. At first a bit weird, but then great.

\section{[Did that experience help you to lose your fear?]}

Yeah, it did big time, about all drugs. I didn't know what to expect. The way I used to think about it was, 'If I take E and then if I realize that I'm freaking out or something or get paranoid and start thinking things are happening to me', what would I do? But certainly when I took it, that didn't happen..

Social interaction within drug scenes led to positions being confirmed, adapted, and, in some cases, discovered or expressed for the first time (McGill, 1989). Put differently, behaviours once deemed risky became routinized or habitualized (Bloor, 1995; Rhodes, 1995). Irrespective of individual levels of drug involvement, a large number of the study's young people described this process of risk socialization (Hunt, 1995) as they described their drug journeys. Perceptions of acceptable risk-taking extended in response to new social experiences and, in many accounts, drugs previously deemed dangerous moved gradually to a position of greater acceptance, enabling individuals to push out the boundaries of risk beyond previously constructed limits of acceptability. To a considerable extent, the study's regular drug users gradually developed an orientation towards drug taking that normalized risk. Within a range of social settings, drug use and drug intoxication fell into the realm of the expected and, while aware of the potential for harm, many young drug users habitually assumed the role of the risk actor. This style of risk-taking emerged strongly from the accounts of weekend stimulant users. 
$E$ is a hard drug because it's a killer. Yeah, it is a dangerous drug, I do it and I'm not saying that it's not. There's fact there that it is, you know, what it does to your body. It's a dangerous drug. But you don't think about it when you're out there. Only the next day. I do think about it when I see it in the paper or something. But you don't think about it until you see it in the paper. My friend collapsed in the shower and his dad found him. That was the next day. Stuff like that and you think about it. You go off it for a few months maybe and then you go back on. You're out one night, you don't think about it.

James, 21 years.

According to James, the 'facts' about ecstasy risks have little bearing on the reality 'out there' within drug scenes, where participants frequently take drugs simply 'without thinking'. Many who engaged in drug use as part of social rituals and routines appeared, at times, to temporarily sideline risk considerations in favour of the intoxicating pleasures of the moment. This style of drug use bears some resemblance to that recently described as 'consumerist' and 'hedonistic' by a number of researchers, but with one important distinction: they do not proffer a 'rational', 'calculative', cost/benefit orientation to drugrelated decision-making (Boys et al., 2000; Breeze, Aldridge, \& Parker, 2001; Coffield \& Gofton, 1994; Parker et al., 1998). Experienced drug users, in particular, described numerous situations in which they consumed drugs routinely, without appraisal. ${ }^{6}$ This is not altogether surprising in view of the rituals and routines that characterize many drug use contexts. When risk is in the background it assumes a lesser degree of relevance and becomes a taken-for-granted aspect of everyday life (Cox \& McKellar, 1999). In these situations, calculation can become 'superfluous' (Shiner \& Newburn, 1996, p. 24). This orientation to drug use appears, at first glance, to counter the legitimizing claims made by many of the study's social/recreational drug users regarding the considered and controlled nature of their drug taking. Alternatively, and more accurately, however, such habitualized drug taking is indicative of the risk culture inherent within many drug scenes: drug taking not only endorses risk-taking, it necessitates willingness to risk. Furthermore, this kind of habitual drug taking almost always incorporated systems of behaviour and response aimed at regulating potential danger. For example, the majority of the study's dance drug users described routine strategies aimed at reducing potential harm. In relation to ecstasy consumption, these included 'sipping' (but not consuming too much) water, staggering the intake of ecstasy over the course of a night out, and restricting use to the company of trusted friends. It was possible, in other words, to 'risk risk' and to simultaneously endeavour to reduce harm. James, for example, whose earlier account highlighted the habitual nature of much drug taking, equally proffered a desire to reduce the risk of harm.

You need to know what you're doing, to have experience of E. You need to drink water. If you're in a bar and you have a pint, get a glass of water as well. That's just a thing you have knocked into your head. Water, drink a few sups and then you'll be grand.

James, 21 years.

Even when engaging in drug use habitually, young people did not simply rely on some kind of cosmic protection; instead, they drew on ideas and practices that supported safer drug use. Some, for example, engaged in 'preventive telling', passing on practical advice to novice users and 'watching out' for first-time experimenters. In this sense, the process of risk socialization introduced and reinforced elements of safety as well as risk, as expressed by James: 'That's just a thing you have knocked into your head'.

The transition to dangerous drugs or risky routes of administration As stated earlier, the vast majority of the study's social/recreational drug users portrayed heroin as a risk boundary that they would not cross. Abstainers and drug takers invariably imparted a picture of heroin users as sick and unwell. Indeed, much of the dialogue about heroin use 
and risk played a role equivalent to 'taboo' and 'sin' (Douglas, 1990, 1992), highlighting a moral dimension to many narratives of unacceptable risk. Injecting drug use was perceived as real 'junkie' behaviour; more than this, it signified a denigration of 'self ': non-heroin users consistently depicted heroin-involved youth as 'dirty' and 'diseased'. This attention to the outer appearance of the body was central to how non-heroin users formulated and conceptualized the risks associated with heroin. It is important, therefore, to briefly examine the accounts of those young people who did cross over into this no-go risk domain.

Practically all of the study's problem drug takers were early risk-takers who initiated tobacco, alcohol, and cannabis use during their early or pre-teen years and quickly built an extensive repertoire of drug experiences. Furthermore, their early immersion in street scenes exposed them to a wide range of mood-altering substances and supported perspectives, activities, and behaviours that prized excess over moderation. Simultaneously, many who articulated the allure of heroin scenes described an almost invigorating interpretation of drug consumption as a way of achieving self-confidence, status, and even respect. It was within these highly esteemed contexts that young people pushed out the boundaries of risk.

[Did you realize what you were getting yourself into?]

I wasn't worried about that at all. I thought it was just, I didn't think l'd have a problem with it, ya know. Where we hung around there was a couple that were on it [heroin], but I (pause) ... they [friends] never seemed to have problems ya know, with it. They were a year or two older and they never had problems so ...

Gerald, 19 years.

Extending the boundaries of normal risk was relatively easy within contexts where hard drug use was tolerated. Within these familiar street-based scenes, 'cautionary tales' (Goffman, 1963) about the dangers of heroin frequently lost their significance. Gerald attempted to make the ideas of risk and control compatible and, like many others, believed in his ability to monitor and control his heroin intake during the experimental stages of use. Such claims about control were effective in marginalizing risk, as the following narrative suggests.

Everyone says, 'I won't get strung out, I know when to stop', everyone says that. Fucking hell, 'Ah now I wouldn't get strung out 'cos I'm not like that'. But we always get strung out. When I started smoking [heroin] like I was saying, 'I can control this', but you can in your bollix.

Sabrina, 18 years.

Within the social settings where these young people hung out, informal controls and prior anti-heroin sentiments were either neutralized or defeated. Indeed, many of the study's young heroin users appeared to drift into heroin use amidst a gradual erosion of soft/hard drug distinctions. Moreover, as heroin careers progressed, young people found themselves negotiating increasingly challenging and precarious choices. The stories told by young people about their progressive heroin involvement were sometimes dramatic and many lacked a clear chronology. However, most of the narratives reveal an unfolding sequence of events, albeit different for each individual, that gradually 'pushed' young people towards increased risk. The drug career of several of the study's young people had, at the time of making the transition to intravenous drug use, shifted towards scoring heroin to prevent getting sick (i.e., experiencing withdrawal symptoms). For a large number, the transition to intravenous drug use arose out of a need to feel normal under mounting financial pressure.

[Can you tell me about the first time you injected?] 
I was up on the landings and had no money and there were people there that didn't smoke gear [i.e., they were injectors] and offered me $2 \mathrm{ml}$ in a barrel, so I took it. Stuck for the gear, no money, nothing. At that stage I didn't care. I just wanted the drug anyway I could. You don't think about all the things that can happen. People that are dying sick that bad, they wouldn't even think of AIDS, they would just do it, end of story.

Edel, 18 years.

Like many others, Edel did not see herself as a victim of circumstance and depicted herself as the lead actor in the matter of her heroin use: 'It's my own fault at the end of the day, me own choice. I said l'd never inject and I did'. However, her 'decision' to inject is sorely in need of contextualization. Young heroin users typically claimed a high degree of autonomy and rejected social determinants as an explanation for their drug use. While remaining respectful of such assertions and, indeed, recognizing that agency is intimately associated with risk, most of the narratives simultaneously point in the opposite direction to the importance of social context and constrained choice in shaping drug use practices and behaviour. Accounts like Edel's illustrate the manner in which the structures and processes within heavy end drug scenes operate to isolate and push young people towards risk. The majority of the study's young heroin users found themselves (suddenly and unexpectedly, in many cases) struggling with a drugs lifestyle without access to scripts that might enable them to regulate or minimize risk. Indeed, their circumstances, both social and personal, militated against the generation of safer scripts. Within these contexts, the boundaries between safe and destructive action became increasingly blurred and many only identified risk in hindsight:

I did take a lot of risks. Sometimes, to be honest with ya, I can't believe some of the things I done. At the time, ya don't realize, ya don't care.

Leonda, 23 years.

Unlike the study's recreational and 'controlled' drug users, the settings they frequented did not necessarily support or encourage safer use practices, due in no small part to the pressures and constraints that epitomize heavy end drug scenes.

\section{'Imagined' drug futures}

We have seen from the presentation of earlier accounts that young people defined different types of drug taking as more or less risky and/or acceptable. Consistent with other research on drug use among the young (Agar \& Reisinger, 2000; McElrath \& McEvoy, 1999; Parker \& Egginton, 2002; Parker et al., 1998), the findings presented demonstrate that young people acquired their drugs knowledge from friends and acquaintances and from personal and collective drug experiences. In this sense, young drug users constructed an alternative discourse of risk founded on their everyday experiences, drawing, in the process, on 'grounded' knowledge that matched the cultural framing of drug use within which they operated. Furthermore, a reflexive awareness was evident in many comments concerning how risk is understood and perceived in different ways for different groups. In other words, young people communicated an awareness of the subjective nature of risk.

It's different for everyone. In this area now, we'd nothing. We had nothing and there was drugs everywhere. So we made these decisions [i.e., we took drugs]. For other people, I don't know? All depends what situation you're in. 
Lorraine's comments suggest a recognition that 'risk is the product of a way of seeing rather than an objective fact' (Lupton \& Tolloch, 2002, p. 324). Correspondingly, young people saw risk perceptions as dynamic, changing for themselves and for others over time and even from day to day. This approach to drug use, incorporating flexibility and a corresponding need for scope for manoeuvre, was especially apparent among those young people who used drugs but did not consider their drug use to be problematic. It is not so surprising, then, that when it came to expressing future drug intentions, several articulated a reluctance to commit to a resolute set of 'standards' or positions. In the following account, Joan drew heavily on past experiences as she anticipated the range of drug-taking options out there and the possibility of trying cocaine, a drug she had not yet used. Underpinning this narrative is a reflexive awareness of the contingency of the future; accordingly and strategically, perhaps, she assumed an ambivalent stance.

[So you wouldn't have any interest in doing coke?]

No.

\section{[You wouldn't?]}

No, but saying that, I said that about $E$ in the last interview, I know that, that I wouldn't take E. Now after I done E like, I am not going to doubt the fact that I am never going to try coke, you know. Like maybe I will and maybe I won't, you know like? But I know for a fact that I wouldn't, I wouldn't get addicted, you know what I mean.

[So what drugs do you think you might take in the future?]

Maybe speed, maybe coke? Probably E. I can't say I know because I don't know. I said I wouldn't take E and I done it so, you know what I mean . . . I could maybe try speed or coke.

Joan, 18 years.

Contingency was accepted by many young people as part of their risk worlds and embraced rather than feared in many cases. This kind of flexibility is arguably required when navigating a more uncertain, rapidly changing world where risk-taking may be a functional necessity (Furlong \& Cartmel, 1997; Parker et al., 1998). Contingency, a characteristic of contemporary modernity (Lash, 1993), sits oddly, however, with the notion of compulsive self-monitoring and rational planning of one's daily life activities, including drug consumption. It is perhaps unsurprising then that, as social actors, many of the study's young people presented a messier and more complex picture of rationality and reflexivity than that presented in Beck's (1992) and Giddens' (1991) theoretical accounts. The construction of drug biographies was indeed a "reflexive project" (Giddens, 1991, p. 32), but not one driven exclusively by a rational, calculative approach to risk. For the study's young people, reflexivity was not solely cognitive, but rather aesthetic, incorporating selfinterpretation and interpretation of their social worlds (Lash \& Urry, 1994). In keeping with this, and assuming 'a self which is at the same time a being-in-the world' (Lash \& Urry, 1994 , p. 6), the drawing and re-drawing of risk boundaries was a practical and existential accomplishment. It is precisely this type of complex social, rather than rational, calculation that influenced young people's everyday understanding and experience of drug-related risk.

\section{Conclusion}

Drug journeys, it appears, are intimately associated with risk. The experiential benefits of drug use expressed by the study's young people, sometimes quite dramatically, provide considerable insight into how the meaning of drug consumption is mobilized. Young people do not spontaneously embrace an ideology of drug use. Rather, through everyday 
interaction, they learn to appreciate, enjoy, endorse, and/or later reject some or all drug use, as part of their 'unfolding lives' (Fox, 1998). This paper has focused on young people's drug stories, including their perspectives, reflections and intentions, as a way of elucidating the flow of experience underpinning their drug journeys. As evidenced in the data presented, different people hold different views and beliefs, not simply about the meaning of risk but, additionally, about the consequences of taking risks. In short, risk is particularly open to social definition and construction (Douglas, 1992). Moreover, risk as a social construct is subject to change, magnification, dramatization, and modification. As young people's stories suggest, drug-related risk was anticipated, ignored, avoided, or rejected from specific, experiential positions, but rarely on the basis of 'expert' warnings about the dangers of illicit substances. Young people drew upon lay discourses and reasoning, a process of 'private reflexivity' (Wynne, 1996) located firmly within the realms of their ongoing social and personal experience. Put differently, young people, including drug users and non-users, 'script' risk as they gain experience in the world (Mayock, 2004); they learn by doing and script elaborations are precisely what such learning is about. Correspondingly, they alter, modify, and innovate scripts to accommodate new drugs, novel use settings, and emergent events, as well as changing perceptions of safety and harm. These essentially communicative scripts are played out in social interaction; they are prone to modification and may be subsequently overturned in response to new or emerging life circumstances and events.

Risk, it appears, is a dynamic mode of perception intimately linked to individual subjectivity in a world of uncertainty. While there were elements of a 'rational purposeful strand' (Breeze et al., 2001, p. 53) in the making and re-making of drug decisions, responses to risk did not hinge on rational probability-based thinking. Contrary then to the findings of some recent research highlighting a cost/benefit calculative orientation to drug use on the part of young people (Boys et al., 2000; Breeze et al., 2001; Coffield \& Gofton, 1994; Parker et al., 1998), the dominant narrative or script emerging from this study suggests a more complex dynamic. Decision-making in the domain of drug use emerged as 'a socially interactive enterprise' (Rhodes, 1997, p. 211) and, in many instances, drug taking was habitual, not calculated (Bloor, 1995). Moreover, a 'hedonistic attitude' can override caution (Shewan, Dalgarno, \& Reith, 2000, p. 450) and the flow and pace of experience within drug scenes may not permit, let alone accommodate, 'reasoned' choice-making. Much of the narrative material suggests that responses to risk were hermeneutic, organized around patterns of symbolic and subjective meanings, and strongly embedded in young people's social experiences. Drug use, therefore, cannot be simply characterized as the rational pursuit of the benefit of risk. Moreover, reasoned choice seems an especially poor explanation for the use of a dangerous drug (Hunt, 2001), and one that is highly stigmatized. Several accounts uncovered significant structural barriers to safe drug use and those young people who became seriously enmeshed in heroin lifestyles found themselves navigating situations and settings within which their personal safety was seriously compromised. It also appears that the discourse of harm minimization widely subscribed to did not always prepare young people for the contingencies of drug taking. At the same time, the widespread tendency was for young people to claim ownership of, and responsibility for, risk. Such assertions are not altogether surprising, however, in view of the moralizing discourses surrounding modern-day consumption practices and behaviour (Lupton, 1993, 1995), which increasingly place the onus on people, as consumers, to make informed, rational choices.

While the 1990s theoretical perspective on young people's drug use is both original and admirable, and enormously important in terms of its rejection of pathological explanations for drug consumption, there is a danger that it overstates the role of cost-benefit rationality in decision-making about drugs. In order to appreciate and respond to risk experiences in late modernity we must be alert to the individualistic manner in which young people may perceive and experience risk and, at the same time, recognize the continuing importance of 
the social and structural processes that act to push young people towards risk (Green, Mitchell, \& Bunton, 2000). It seems important, in this context, to remind ourselves that agency is something that is 'done', but how people go about 'doing drugs' is what is important. Young people may calculate and apply rational thinking to their drug and/or other risk-related decisions. Equally, however, activities engaged in for the benefit of risk may themselves become routine, and inevitably take place according to certain boundaries, norms, assumptions, or scripts. Like other constructs we use to describe social phenomena, risk acts as a lens and can sharpen, or alternatively obscure, our understanding of such phenomena. The concept of risk and the way it operates has implications for how we think about drugs, about our and others' use of substances, and about the nature, form, and ideology of interventions designed to forestall or delay entry into all or specific types of drug use. Risk discourses both delimit and make possible what can be said and done about the drug use phenomenon since they serve to organize the way in which we conceive of and deal with the 'danger' posed by drug taking, both at the level of the individual and of society at large. This paper has demonstrated the limits of individualism in accounting for how young people arrive at drug decisions, both at specific 'moments' and over time. Nonetheless, the public response to risk has become individualized (Douglas, 1992). This is reflected, for example, in the dominant focus of prevention and harm reduction strategies and interventions in Western industrialized countries, which are directed, in the main, toward individual risk behaviour change (Rhodes, 2002). The major strategies centre on providing information and advice to drug users on how to minimize risk; they encourage drug users to take responsibility for harm and assume, to a considerable extent, that they are able to manage risk. Indeed, today's drug users appear to be viewed as more enterprising, prudent, and self-managing subjects (O'Malley, 1999). This individualization of risk reduction fails, however, to capture the complex and nuanced nature of much risk-related behaviour. It also neglects the situational pressures and constraints on 'safe' drug use and fails to take account of the social, cultural, and economic contexts that structure much risky drug use (Moore, 2004). The risk behaviours and practices typically targeted through harm reduction strategies are, in other words, detached from the immediate situation of action.

Belief in the rational calculability of drug-related risk, and in the practical ability of young drug users to self-govern the risks to which they may be potentially exposed, is always in danger of foundering upon its own inherent limits. In keeping with developments in other European countries and in Australia, harm reduction policies were introduced in Ireland in response to the 1980 s public health crisis associated with HIV/AIDS. The introduction of these policies signalled 'a new style of risk construction in terms of the health implications of drug use' (Butler, 2002, p. 176). Twenty years on, Ireland can boast many new innovations, and harm reduction initiatives have expanded dramatically, particularly since 1995 (Mayock, 2003). Nonetheless, mounting evidence of continued borrowing and lending of injecting paraphernalia, particularly among younger injecting drug users (Mullen \& Barry, 1999; Smyth, Keenan, \& O'Connor, 1999), coupled with growing concern over hepatitis C transmission rates (Allwright, Barry, Bradley, Long, \& Thornton, 1999; Long et al., 2001), all point to significant challenges and failures within current harm reduction practice.

Facilitating behaviour change and encouraging safer drug scripts requires more than individually targeted messages and interventions. If the objective is to bring about change in the social etiquette of drug use in order to prevent or minimize harm, this is unlikely to be realized through 'hypersanitary' messages

(Bourgois, 1998, p. 2334) that do not accord with the experience of much drug taking, much less the social and economic imperatives of risky drug use. While direct information and advice about safe drug use will always be an important component of harm reduction practice, this needs to be supported by greater attention to the settings and contexts that spawn risk. Put differently, rather than viewing risk (and opportunities to reduce harm) as located in and with the individual, we need to focus on the risk environments (Rhodes, 2002) that create vulnerability to risky drug use practices. In relation to young people who 
live in socially excluded 'zones' where drug problems traditionally cluster, there is an urgent need to recognize diversity among young drug users and the consequent need for varied and innovative strategies and responses. Clearly, not all young people who live in socially disadvantaged communities will immerse themselves in 'heavy end' drug scenes and the majority will, if anything, remain committed to boundaries that reject hard drug use.

Nonetheless, a minority may embark upon hard drug careers and find themselves operating within marginal social scenes where the boundaries separating safety and risk become increasingly blurred. This paper has highlighted the environments in which young people move as crucial determinants of how risk is scripted. It follows that responsibility for harm lies not solely with the individuals who are charged with negotiating these environments, but also with the social, economic, and political structures that create susceptibility and, in some cases, exceptional vulnerability to drug-related harm.

\section{Notes}

1. Parker et al. (1998, p. 150) do not claim that cost-benefit analysis is the only component of drug decisions. For example, they state that 'whilst rational decision making usually guides, it many not dominate'. The authors also caution against the use of the cost-benefit equation as a 'mechanical explanation' (Parker et al., 1998, p. 148). They do, however, advance cost-benefit analysis as a key conceptual tool for understanding young people's drug journeys.

2. All of the study's focus group participants were also interviewed individually. Due to practical problems of access (related to the fragmentation of peer groups and changes in young people's 'hanging out' routines), it was not possible to arrange focus groups during Phase II fieldwork.

3. The follow-up sample of 42 young people included 12 abstainers, 15 drug takers, and 15 problem drug takers.

4. A number of recent studies have, however, drawn attention to the centrality of pleasure to drug consumption (Henderson, 1993, 1997; Measham et al., 2001; Parker et al., 1998; Williams \& Parker, 2000).

5. 'Normal risk', according to Hunt (1995, p. 442), 'is a dynamic category which is continually negotiated', largely in interaction with others. In the case of Hunt's (1995) deepsea divers, the process of risk socialization involved learning, making distinctions between 'normal' and 'excessive' risk, and developing accounts and techniques that help to neutralize anxiety. Becker's (1963) account of the complex learning process involved in becoming a marijuana user has many similarities. According to Becker, the novice first learns to inhale and, at a later stage, learns to appreciate the effects of the drug. This shift from being a naive user to becoming an experienced user strongly emphasises a process of socialization associated with the adaptation of behaviour and a subsequent acquired ability to enjoy the drug experience.

6. Ethnographic observations confirm this orientation towards some drugs. For example, when young people congregated at outdoor locations, they frequently shared a joint or rubbed speed on their gums as they chatted and engaged in routine socialization. These drug-taking activities proceeded casually and without any apparent concern for drug-related risk.

\section{Acknowledgements}

I want to thank Dr Shane Butler, Social Studies Department, Trinity College, for the guidance he provided throughout the conduct of this research and for his comments on earlier drafts of this paper. I also wish to acknowledge the research funding received from the Addiction Research Centre, Trinity College, Dublin, the Irish Research Council for the Humanities and Social Sciences, and the Trinity Foundation, Trinity College, Dublin. 


\section{References}

Agar, M., \& Reisinger, H. S. (2000). Explaining drug trends: Suburban heroin use in Baltimore county. In A. Springer \& A. Uhl (Eds.), Illicit drugs: Patterns of usepatterns of response. Proceedings on the 10th Annual ESSD Conference on Drug Use and Drug Policy in Europe (pp. 143-165). Innsbruck: Studien Verlag.

Allwright, S., Barry, J., Bradley, F., Long, J., \& Thornton, L. (1999). Hepatitis B, hepatitis C and HIV in Irish prisoners: Prevalence and risk. Dublin: Government Publications.

Beck, U. (1992). Risk society: Towards a new modernity. London: Sage.

Beck, U. (1997). The reinvention of politics. Cambridge: Polity Press.

Becker, H. (1963). Outsiders: Studies in the sociology of deviance. New York: The Free Press.

Biernacki, P., \& Waldorf, D. (1981). Snowball sampling. Sociological Methods Research, 10, 141-163.

Bloor, M. (1995). The sociology of HIV transmission. London: Sage.

Bloor, M., McKeganey, N., Finlay, A., \& Barnard, M. A. (1992). The inappropriateness of psycho-social models of risk behaviour for understanding HIV-related risk practices among Glasgow male prostitutes. AIDS Care, 4, 2, 131-137.

Bourgois, P. (1998). The moral economies of homeless heroin addicts: Confronting ethnography, HIV risk, and everyday violence in San Francisco shooting encampments. Substance Use and Misuse, 33, 11, 2323-2351.

Boys, A., Fountain, J., Marsden, J., Griffiths, P., Stillwell, G., \& Strang, J. (2000). Drug decisions: A qualitative study of young people. London: Health Education Authority.

Breeze, J., Aldridge, J., \& Parker, H. (2001). Unpreventable? How young people make and remake drug-taking decisions. In H. Parker, J. Aldridge \& R. Egginton (Eds.), UK drugs unlimited: New research and policy lessons on illicit drug use (pp. 51-79). New York: Palgrave.

Butler, S. (2002). Alcohol, drugs and health promotion in modern Ireland. Dublin: Institute for Public Administration.

Calafat, A., Bohrn, K., Juan, M., Kokkevi, A., Maalste, N., Mendes, F., et al. (1999). Night life in Europe and recreative drug use. Valencia: Irefrea and European Commission.

Coffield, F., \& Gofton, L. (1994). Drugs and young people. London: Institute for Public Policy Research.

Comiskey, C. (1998). Estimating the prevalence of opiate use in Dublin, Ireland during 1996. Dublin: Department of Health and Children.

Cox, S. M., \& McKellar, W. (1999). 'There's this thing in our family': Predictive testing and the construction of risk of Huntington disease. Sociology of Health and IIIness, 21, 5, 622-646.

Dean, G., Lavelle, P., Butler, M., \& Bradshaw, J. S. (1984). Characteristics of heroin and non-heroin users in a North-Central Dublin area. Dublin: Medico-Social Research Board.

Dean, G., O'Hare, A., O'Connor, A., Kelly, M., \& Kelly, G. (1985). The opiate epidemic in Dublin, 1979-1983. Irish Medical Journal, 78, 4, 107-110.

Denscombe, M. (1993). Personal health and the social psychology of risk-taking. Health Education Research, 8, 505-517.

Douglas, M. (1990). Risk as a forensic resource. Daedalus, 119, 1-16.

Douglas, M. (1992). Risk and blame: Essays in cultural theory. London: Routledge.

European Monitoring Centre for Drugs and Drug Addiction (2002). Annual report on the state of the drugs problem in the European Union. Lisbon: European Monitoring Centre for Drugs and Drug Addiction. 
European Monitoring Centre for Drugs and Drug Addiction (2003). Annual Report 2003: The state of the drugs problem in the European Union and Norway. Luxembourg: Office for Official Publications of the European Communities.

Featherstone, M. (1995). Undoing culture: Globalisation, postmodernism and identity. London: Sage Publications.

Feldman, H. (1968). Ideological supports to becoming and remaining a heroin addict. Journal of Health and Social Behaviour, 9, 2, 131-139.

Fox, N. (1998). 'Risks', 'hazards' and life choices: Reflections on health at work. Sociology, $32,4,665-687$.

France, A. (2000). Towards a sociological understanding of youth and their risk-taking. Journal of Youth Studies, 3, 3, 317-313.

Friedman, S. R., Curtis, R., Neaigus, A., Jose, B., \& Desjarlais, D. C. (1999). Social networks, drug injectors' lives, and HIV/AIDS. New York: Kluwer Academic/Plenum Publishers.

Furlong, A., \& Cartmel, F. (1997). Young people and social change. Buckingham: Open University Press.

Giddens, A. (1991). Modernity and self-identity: Self and society in the late modern age. Cambridge: Polity Press.

Goffman, E. (1963). Stigma: Notes on the management of spoiled identity. New York: Prentice Hall.

Green, E., Mitchell, W., \& Bunton, R. (2000). Contextualising risk and danger: An analysis of young people's perceptions of risk. Journal of Youth Studies, 3, 2, 109-126.

Hart, G., \& Boulton, M. (1995). Sexual behaviour in gay men: Towards a sociology of risk. In P. Aggleton, P. Davis \& G. Hart (Eds.), AIDS: Safety, sexuality and risk (pp. 55-67). London: Flamer Press.

Henderson, S. (1993). Fun, fashion and frisson. International Journal of Drug Policy, 4, 3, 122-129.

Henderson, S. (1997). Ecstasy: Case unsolved. London: Pandora.

Henderson, S. (1999). Drugs and culture: The question of gender. In N. South (Ed.), Drugs: Cultures, controls \& everyday life (pp. 36-48). London: Sage.

Hibell, B., Andersson, B., Ahlstrom, S., Balakireva, O., Bjarnasson, T., Kokkevi, A., et al. (2000). The 1999 ESPAD report: Alcohol and other drug use among students in 30 European countries. Stockholm: Council of Europe, Pompidou Group.

Hibell, B., Andersson, B., Bjarnasson, T., Kokkevi, A., Morgan, M., \& Narusk, A. (1997). The 1995 ESPAD report: Alcohol and other drug use among students in 26 European countries. Stockholm: Council of Europe, Pompidou Group.

Hunt, J. (1995). 'Divers' accounts of normal risk. Symbolic Interaction, 18, 4, 439-462.

Hunt, N. (2001). Reasoning and restricted choices within recreational repertoires. International Journal of Addiction, 12, 425-428.

Kohn, M. (1997). The chemical generation and its ancestors: Dance crazes and drug panics across eight decades. International Journal of Drug Policy, 8, 3, 137-142.

Lash, S. (1993). Reflexive modernisation: The aesthetic dimension. Theory, Culture \& Society, 10, 1-23.

Lash, S., \& Urry, J. (1994). Economies of signs \& space. London: Sage.

Long, J., Allwright, S., Barry, J., Reaper-Reynolds, S., Thornton, L., Bradley, F., et al. (2001). Prevalence of antibodies to hepatitis $B$, hepatitis $C$, and HIV and risk factors in entrants to Irish prisons: A national cross sectional survey. British Medical Journal, $343,1-6$.

Lupton, D. (1993). Risk as moral danger: The social and political functions of risk discourse in public health. International Journal of Health Services, 23, 3, 425-435. 
Lupton, D. (1995). The imperative of health: Public health and the regulated body. London: Routledge.

Lupton, D. (1999). Risk. London: Routledge.

Lupton, D., \& Tulloch, J. (2002). 'Risk is part of your life': Risk epistemologies among a group of Australians. Sociology, 36, 2, 317-334.

MacDonald, R., \& Marsh, J. (2001). Disconnected youth? Journal of Youth Studies, 4, 4, 373-391.

MacDonald, R., \& Marsh, J. (2002). Crossing the Rubicon: Youth transitions, poverty, drugs and social exclusion. International Journal of Drug Policy, 13, 27-38.

Mayock, P. (2001). Cocaine use in Ireland: An exploratory study. In R. Moran, L. Dillon, M. O'Brien, P. Mayock, E. Farrell \& B. Pike (Eds.), A collection of papers on drug issues in Ireland (pp. 80-152). Dublin: Health Research Board.

Mayock, P. (2003, September). Young people, alcohol and drugs: Reviewing the Irish harm reduction experience. Paper presented at the Addiction Research Centre Third Annual Conference, Trinity College, Dublin.

Mayock, P. (2004, April). Contextualising risk and harm: An analysis of young people's perceptions. Proceeding of the 15th International Conference on the Reduction of Drug-Related Harm, Melbourne, Australia, Abstract 726.

McElrath, K., \& McEvoy, K. (1999). Ecstasy use in northern Ireland. Belfast: Department of Sociology and Social Policy and Institute of Criminology and Criminal Justice, Queens University, Belfast.

McGill, S. (1989). Risk perception and the public: Insights from research around Sellafield. In J. Brown (Ed.), Environmental threats: Perception, analysis and management (pp. 48-66). London: Belhaven Press.

Measham, F. (2002). 'Doing gender'-'doing drugs': Conceptualising the gendering of drugs cultures. Contemporary Drug Problem, 29, 2, 335-373.

Measham, F., Aldridge, J., \& Parker, H. (2001). Dancing on drugs: Risk, health and hedonism in the British club scene. London: Free Association Books.

Mitchell, W. A., Crawshaw, P., Bunton, R., \& Green, E. E. (2001). Situating young people's experiences of risk and identity. Health, Risk and Society, 3, 2, 217-233.

Moore, D. (2004). Governing street-based injecting drug users: A critique of heroin overdose prevention in Australia. Social Science and Medicine, 59, 1547-1557.

Mugford, S. K., \& O'Malley, P. (1991). Heroin policy and deficit models: The limits of left realism. Crime, Law and Society, 15, 19-36.

Mullen, L., \& Barry, J. (1999). Needle exchange in the eastern health board region: An analysis of first attenders, 1990-1997. Dublin: Eastern Health Board.

Nettleton, S. (1997). Governing the risky self: How to become healthy, wealthy and wise. In A. Petersen \& R. Bunton (Eds.), Foucault, health and medicine (pp. 207-222). London: Routledge.

O'Malley, P. (1999). Consuming risks: Harm minimisation and the government of "drug users". In R. Smandych (Ed.), Governable places: Readings on governmentality and crime control. Aldershot: Ashgate.

Parker, H., Bakx, K., \& Newcombe, R. (1988). Living with heroin: The impact of a drugs "epidemic" on an English community. Milton Keynes: Open University Press.

Parker, H. \& Egginton, R. (2002). Adolescent recreational alcohol and drug careers gone wrong: Developing a strategy for reducing risks and harms. International Journal of Drug Policy, 13, 419-432.

Pearson, G., Gilman, M., \& Mclver, S. (1986). Young people and heroin: An examination of heroin use in the North of England. Health Education Council Report No. 8. London: Health Education Council. 
Parker, H., Measham, F., \& Aldridge, J. (1998). Illegal leisure: The normalisation of adolescent recreational drug use.London: Routledge.

Petersen, A. (1996). Risk and the regulated self: The discourse of health promotion as politics of uncertainty.Australian and New Zealand Journal of Sociology, 32, 1, 44-57.

Rhodes, T. (1995). Theorising and researching 'risk': Notes on the social relations of risk in heroin users' lives In P. Aggleton, P. Davies \& G. Hart (Eds.), AIDS: Safety, sexuality and risk (pp. 125-143). London: Taylor \& Francis.

Rhodes, T. (1997). Risk theory in epidemic times: Sex, drugs and the social organisation of 'risk behaviour'. Sociology of Health and Illness, 19, 2, 208-227.

Rhodes, T. (2002). The 'risk environment': A framework for understanding and reducing drug-related harm. International Journal of Drug Policy, 13, 85-94.

Rhodes, T., Lilly, R., Ferna'ndez, C., Giorgino, E., Kemmesis, U. E., Ossebaard, H. C., et al. (2003). Risk factors associated with drug use: The importance of 'risk environment'. Drugs: Education, prevention and policy, 10, 4, 303-329.

Sherman, S. G., Smith, L., Laney, G., \& Strathdee, S. A. (2002). Social influences on the transition to injection drug use among young heroin sniffers: A qualitative analysis. International Journal of Drug Policy, 13, 113-120.

Shewan, D., Dalgarno, P., \& Reith, G. (2000). Perceived risk and risk reduction among ecstasy users: The role of drug, set and setting. International Journal of Drug Policy, 10, 431-453.

Shiner, M., \& Newburn, T. (1996). The youth awareness programme: An evaluation of a peer education drugs project. London: Central Drugs Prevention Unit, Home Office.

Smyth, B. P., Keenan, E., \& O'Connor, J. (1999). Evaluation of the impact of Dublin's expanded harm-reduction programme on prevalence of hepatitis $\mathrm{C}$ among short-term injecting drug users. Journal of Epidemiology and Community Health, 53, 434-435.

South, N. (1999). Debating drugs and everyday life: Normalisation, prohibition and 'otherness'. In N. South (Ed.), Drugs: Cultures, controls and everyday life (pp. 1-15). London: Sage.

Watters, J. K., \& Biernacki, P. (1989). Targeted sampling: Options for the study of hidden populations. Social Problems, 36, 4, 416-430.

Wax, M. (1967). On misunderstanding Verstehen: A reply to Abel. Sociology and Social Research, 51, 323-333.

Weinstein, R. (1980). Vocabularies of motive for illicit drug use: An application of the accounts framework. The Sociological Quarterly, 21, 577-593.

Williams, L., \& Parker, H. (2001). Alcohol, cannabis, ecstasy and cocaine: Drugs of reasoned choice amongst young adult recreational drug uses in England. International Journal of Drug Policy, 12, 397-413.

Wynne, B. (1996). May sheep safely graze? A reflexive view of the expert-lay knowledge divide. In S. Lash, B. Szerszynski \& B. Wynne (Eds.), Risk, environment and modernity: Towards a new ecology (pp. 44-83). London: Sage. 